DOSSIÊ TEMÁTICO: Política de Educação Superior

\title{
TENDÊNCIA DA PRODUÇÃO CIENTÍFICA SOBRE OS CURSOS SUPERIORES DE TECNOLOGIA NO BRASIL
}

\author{
TRENDS OF SCIENCE PRODUCTION ABOUT TECHNOLOGY HIGHER COURSES IN \\ BRAZIL
}
TENDENCIAS DE LA PRODUCCIÓN CIENTÍFICA ACERCA DE LOS CURSOS SUPERIORES DE TECNOLOGÍA EN BRASIL

\author{
José dos Santos Souza \\ Universidade Federal Rural do Rio de Janeiro - Brasil \\ Célia Cristina Pereira da Silva Veiga \\ Universidade Federal Rural do Rio de Janeiro - Brasil
}

\begin{abstract}
Resumo: O artigo analisa a produção científica sobre os Cursos Superiores de Tecnologia (CSTs) publicada em cinco repositórios brasileiros no período de 1978 a 2017. Desde meados dos anos 2000, no bojo das reformas educacionais empreendidas no Brasil, percebe-se a ampliação do número de CSTs. Paralelamente, percebe-se também o aumentado da produção científica sobre a origem e o desenvolvimento desse grau acadêmico. O objetivo do artigo é explicitar as principais tendências da produção científica acerca dos CSTs no Brasil. Foram levantadas 666 produções científicas que mencionam os CSTs, mas dentre estas havia somente 476 produções cujo objeto de análise são os CSTs. A partir de uma análise destas produções, verificou-se que a maior parte delas é produzida na Região Sudeste e Sul do país, por pesquisadores vinculados a instituições públicas de ensino superior e podem ser classificadas em 3 categorias de abordagem: 1) Aspectos Pedagógicos dos CSTs; 2) Política e Regulação dos CSTs; e 3) Aspectos Profissionais da implantação e desenvolvimento dos CSTs. Estudos que tratam dos aspectos pedagógicos dos CSTs são os mais numerosos. Percebeu-se que a literatura analisada expressa duas concepções distintas e antagônicas de formação humana: a concepção interessada de formar o trabalhador para atender as demandas do mercado e a concepção de formar o trabalhador numa perspectiva unitária e omnilateral.
\end{abstract}

Palavras-chave: Curso Superior de Tecnologia; Educação Tecnológica; Produção Científica.

\begin{abstract}
The article analyzes the scientific production on the Technology Higher Courses (THCs) published in five Brazilian repositories from 1978 to 2017. Since the mid-2000s, in the midst of educational reforms undertaken in Brazil, there has been an increase in the number of THCs. At the same time, also it realizes increased the scientific literature on the origin and development of this academic degree. The purpose of the article is to explain the main trends in scientific production about THCs in Brazil. 666 scientific works have been found that mention the THCs, but among these there were only 476 works whose object of analysis are the THCs. From the analysis of these works, it was found that most of them are produced in the Southeast and South of the country, by researchers linked to public institutions of higher education and can be classified into 3 categories of approach: 1) pedagogical aspects of THCs; 2) THCs policy and regulation; and 3) Professional aspects of the implementation and development of THCs. Studies dealing with the pedagogical aspects of THCs are
\end{abstract}


the most numerous. It was noticed that the analyzed literature expresses two distinct and antagonistic conceptions of human formation: the conception interested in training the worker to meet market demands and the conception of training the worker in a unitary and omnilateral perspective.

Keywords: Technology Higher Courses; Technological Education; Scientific Production.

Resumen: El artículo analiza la producción científica en los Cursos Tecnológicos Superiores (CSTs) publicados en cinco repositorios brasileños de 1978 a 2017. Desde mediados de la década de 2000, en medio de las reformas educativas emprendidas en Brasil, ha habido un aumento en el número de CSTs. Al mismo tiempo, también se da cuenta de una mayor literatura científica sobre el origen y desarrollo de este grado académico. El propósito del artículo es explicar las principales tendencias en la producción científica sobre los CSTs en Brasil. Se han encontrado 666 trabajos científicos que mencionan los CSTs, pero entre estos solo había 476 trabajos cuyo objeto de análisis son los CSTs. A partir del análisis de estos trabajos, se descubrió que la mayoría de ellos son producidos en el Sureste y Sur del país, por investigadores vinculados a instituciones públicas de educación superior y pueden clasificarse en 3 categorías de enfoque: 1) aspectos pedagógicos de los CSTs; 2) política y regulación de los CSTs; y 3) aspectos profesionales de la implementación y desarrollo de CSTs. Los estudios que abordan los aspectos pedagógicos de los CSTs son los más numerosos. Se observó que la literatura analizada expresa dos concepciones distintas y antagónicas de la formación humana: la concepción interesada en capacitar al trabajador para satisfacer las demandas del mercado y la concepción de capacitar al trabajador en una perspectiva unitaria y omnilateral.

Palabras clave: Curso Superior de Tecnología; Educación Tecnológica; Producción científica.

\section{Introdução}

Este artigo analisa o tratamento que a literatura científica tem dispensado aos Cursos Superiores de Tecnologia (CSTs). Para isto, foram abordadas as principais tendências da produção científica sobre os CSTs e verificado se no conjunto delas o conflito de classes e a forma como ele se materializa na conjuntura atual do país foram considerados. A análise parte do pressuposto de que a concepção de formação humana que orienta a política de desenvolvimento dos CSTs no Brasil é pautada por uma perspectiva pragmática, imediatista e interessada de formação humana, contraposta à perspectiva unitária e omnilateral construída no contexto do movimento organizado dos trabalhadores contra o capital cujos fundamentos teóricos e metodológicos estão muito bem sistematizados por Marx e Engels (2011), Gramsci (1999; 2000a; 2000b; 2001), Pistrak (2000; 2013) e Manacorda (2017), dentre tantos outros.

Nessa perspectiva, a análise aqui apresentada resulta de uma pesquisa básica, de análise qualitativa, de caráter exploratório, que se enquadra na categoria de uma pesquisa bibliográfica cujas fontes de dados são os repositórios brasileiros mais relevantes na área de ciências humanas e sociais, tais como: o Scientific Electronic Library Online (SciELO); o Indexador Online de Periódicos na Área da Educação (Educ@), da Fundação Carlos Chagas Filho; o Catálogo de 
Teses da Coordenação de Aperfeiçoamento de Pessoal do Ensino Superior (CAPES); a Biblioteca Online da Associação Nacional de Pós-Graduação e Pesquisa em Educação (ANPEd) - especificamente os trabalhos apresentados em suas reuniões anuais; e o Banco Nacional de Dissertações e Teses Digitais (BDTD) do Instituto Brasileiro de Informação em Ciência e Tecnologia (IBICT). Na realidade, este estudo exploratório foi desenvolvido para subsidiar nossas investigações sobre o processo de implantação e desenvolvimento da educação tecnológica no Brasil e tem como objetivo explicitar as diferentes tendências analíticas da literatura sobre os CSTs no Brasil.

A análise das tendências em construção no processo de implantação e desenvolvimento dos cursos superiores de tecnologia no Brasil revelam, necessariamente, a disputa na arena política da sociedade brasileira nestes últimos anos. Para compreender esta disputa, é preciso considerar o trabalho na sua essência, ou seja, enquanto utilização da força de trabalho e, por conseguinte, o trabalhador, como força de trabalho em ação ou, até mesmo, em potencial. Tal concepção fundamenta-se na afirmação de Marx (2017) de que a utilização da força de trabalho para a produção de valor-de-uso deve ser considerada à parte de qualquer estrutura social determinada, haja vista que em qualquer ordem social, seja comunista ou capitalista ou qualquer outra, a utilização da força de trabalho para a produção de mercadorias seria indispensável à própria sociabilidade. Daí decorrem três observações importantes: a) há um forte conteúdo ideológico em torno das diferentes concepções de trabalho e de formação humana presentes na sociedade de classes; b) a concepção do trabalho e de formação humana na perspectiva da sociedade de classes mascara a apropriação privada do trabalho excedente e a extração da maisvalia por meio do fetiche da mercadoria; e c) as diferentes concepções educacionais estão articuladas às diferentes concepções de organização das forças produtivas presentes na sociedade de classe.

Para a exposição de nossa análise, buscamos explicitar as características da produção científica levantada, bem como identificar os temas e tendências em discussão nela. A organização e análise das principais características presentes na literatura levantada nos permitiu construir uma ideia do panorama geral do pensamento acadêmico acerca dos CSTs. Para esta caracterização, tomamos como parâmetro a origem geográfica, o vínculo IES dos autores, a cronologia e as áreas de conhecimento a partir das quais foram originadas as produções científicas. A partir desta caracterização, foi possível estender nossa análise para a identificação dos principais temas e tendências presentes na produção científica levantada, de modo a classificar cada produto científico levantado de acordo com seus vínculos temáticos. 
Isto nos permitiu compor um panorama representativo da literatura sobre os CSTs, de modo a explicitar suas principais tendências e perspectivas teóricas e metodológicas.

Nossa expectativa é de que este texto sirva de referência para o desenvolvimento de novas pesquisas sobre a formação profissional tecnológica no país, na medida em que ele oferece uma visão representativa da literatura sobre os CSTs, suas principais tendências e suas origens institucionais e geográficas.

\section{Características Gerais da Produção Científica sobre os CSTs}

Uma vez estabelecidas as palavras-chave que nos serviram como termos de busca, foi possível levantar 666 produções científicas de diferentes tipos ${ }^{1}$, a saber: 02 apresentações de pôster e 01 palestra em evento científico, 24 artigos científicos, 517 dissertações de mestrado e 122 teses de doutorado.

Classificamos as 666 produções científicas levantadas por região geográfica do país, considerando o vínculo institucional dos autores. Notamos que quase $80 \%$ delas têm origem na Regiões Sudeste $(51 \%)$ e Sul $(28 \%)$. Os $21 \%$ restantes se referem a produções científicas originárias das regiões Nordeste (12\%), Centro-oeste $(8 \%)$ e Norte $(1 \%)$. Cabe ressaltar que pesquisadores do estado de São Paulo são responsáveis por mais de $30 \%$ das produções científicas levantadas. Por outro lado, não foram encontradas produções científicas sobre o tema nos estados de Roraima, Acre, Tocantins, Piauí, Amapá e Maranhão. Coincidentemente, essas últimas unidades federativas figuram entre aquelas que menos ofertaram CSTs, o que leva a menor número de ingressos e concluintes, de acordo com os dados do Censo da Educação Superior (INEP, 2018). Desse modo, percebe-se indícios de existência de certa relação entre oferta de CSTs e produção científica sobre esse tema por região do país. A Região Sudeste, por exemplo, comporta a maior oferta de CSTs, como também a maior produção científica sobre o tema.

\footnotetext{
${ }^{1}$ Ao aplicarmos as palavras-chave como termos de busca, chegamos a um total de 1.219 produções científicas. Entretanto, percebemos algumas situações que mereciam ajustes, são elas: havia casos em que uma mesma produção científica havia sido buscada por palavras-chaves distintas; casos em que uma mesma produção científica constava em mais de um repositório; e até casos em que uma mesma produção científica constava mais de uma vez em um único repositório. Estas situações geraram repetições que precisaram ser eliminadas. Isto nos obrigou a fazer uma filtragem para eliminar itens repetidos e chegarmos ao número real de 666 produções científicas levantadas.
} 


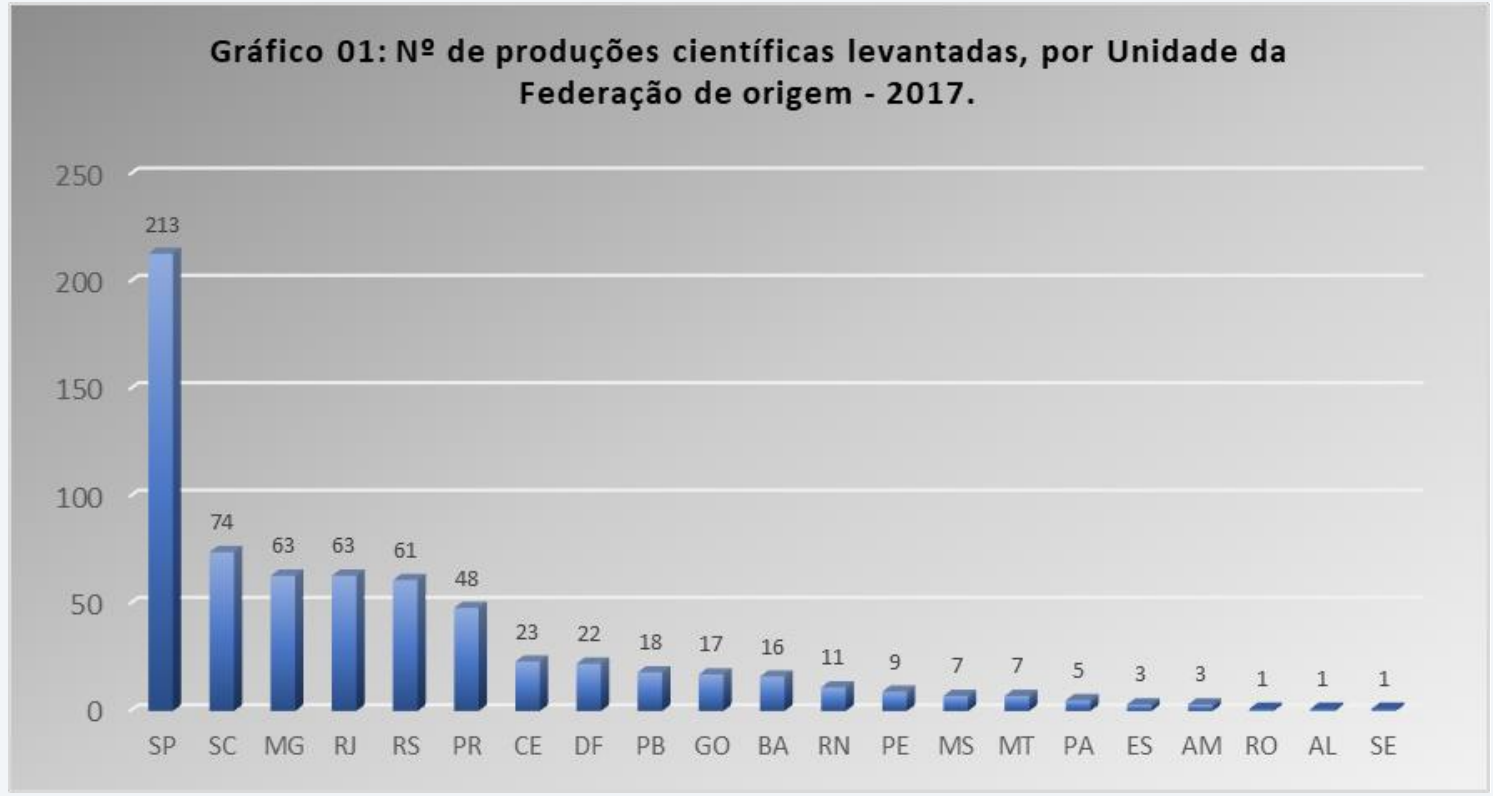

Fonte: dados coletados pelos autores, elaboração própria

No que se refere ao perfil das instituições de origem das produções científicas levantadas, 62,9\% vêm de instituições públicas e $37,1 \%$ de instituições privadas, o que confirma a superioridade do setor público na produção científica do país e que isto se expressa também na produção científica sobre os CSTs. A Universidade Federal de Santa Catarina (UFSC) destacase nesse sentido, sendo responsável por 6,2\% do total da literatura levantada. Outra observação interessante é que 80\% desta produção vêm de apenas 51 Instituições de Ensino Superior (IES), embora existam 2.448 IES no Brasil (INEP, 2018).

Tabela 01: $\mathrm{N}^{\mathrm{o}}$ de produções científicas levantadas, por dependência administrativa das IES de origem dos autores - 2017.

\begin{tabular}{lcc} 
Dependência Administrativa & № & \% \\
\hline Pública & 419 & 62,9 \\
Privada & 247 & 37,1 \\
Sem fins lucrativos & 147 & 22,1 \\
Com fins lucrativos & 100 & 15,0 \\
Total & $\mathbf{6 6 6}$ & $\mathbf{1 0 0 , 0}$
\end{tabular}

Fonte: dados coletados pelos autores, elaboração própria

A cronologia das produções científicas levantadas demonstra que, desde 1978, vêm sendo realizados trabalhos científicos sobre os CSTs. Contudo, o período de 2010 a 2016 foi o intervalo com maior quantitativo de produções (65\%) e a produção referente ao período de 2005 a 2016 corresponde a 90\% do total. Portanto, esse período é o auge da produção científica sobre o tema em 39 anos. Observe-se que este período coincide com os mandatos de Lula da Silva e de Dilma Rousseff na Presidência da República (2003-2016), momento em que houve substantiva ampliação da oferta de ensino superior no país, inclusive de CSTs, fruto da política 
de expansão do ensino superior promovida por esses governos por meio de programas como: o Fundo de Financiamento Estudantil (FIES), o Programa Universidade para Todos (PROUNI) e o Programa de Reestruturação e Expansão das Universidades Federais (REUNI).

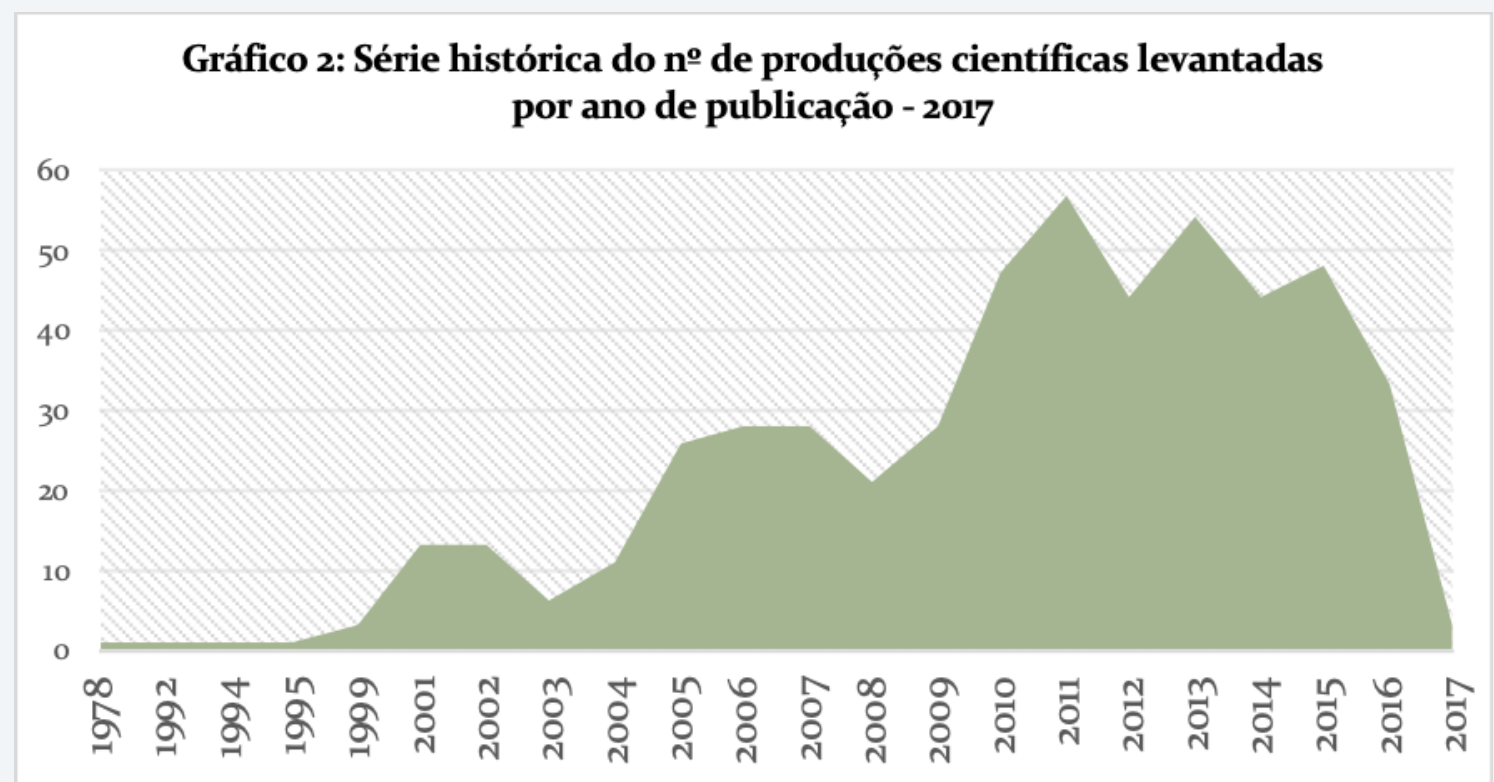

Fonte: dados coletados pelos autores, elaboração própria

As 666 produções científicas levantadas foram organizadas a partir de cinco categorias de análise. As três primeiras categorias foram escolhidas tomando como pressuposto o entendimento de que a educação profissional compreende, principalmente, três categorias de perspectiva analítica: o trabalho, a educação e a política. Sendo os CSTs relacionados ao campo de educação profissional no Brasil, as produções científicas que os tomam como objeto também podem ser agrupadas a partir da mesma categorização. Nesse sentido, a primeira categoria que adotamos se destina às produções científicas que abordaram problemas relacionados aos “Aspectos Profissionais nos CSTs". A segunda destina-se às produções científicas que abordaram problemas relacionados à "Política e Regulação dos CSTs". A terceira destina-se às produções científicas que abordaram problemas relacionados aos "Aspectos Pedagógicos dos CSTs". Além dessas, foi necessária a adoção de uma quarta categoria destinada às produções científicas que trataram de "Outras questões acerca dos CSTs" e uma quinta categoria destinada às produções científicas cujo objeto de análise "Não é Pertinente aos CSTs”, apesar de terem em seus títulos, resumos ou palavras-chave algum termo de busca por nós utilizado.

As três primeiras categorias escolhidas foram divididas em subcategorias para melhor organização dos dados encontrados. A primeira categoria, denominada “Aspectos profissionais 
nos CSTs", foi dividida em seis subcategorias. Essa subdivisão levou em consideração a organização dos 13 eixos de formação tecnológica presentes no Catálogo Nacional de Cursos Superiores de Tecnologia (CNCSTs) (BRASIL, 2016a). Para uma melhor classificação das produções desta última categoria de acordo com os eixos indicados no CNCSTs, agrupamos alguns deles e assim ficou: 1) a "formação ambiental", que compreende os eixos: "ambiente e saúde" e "recursos naturais"; 2) a "formação para o trabalho na indústria", que compreende os eixos: "controle e processos industriais", "produção industrial" e "produção alimentícia"; 3) a "formação cultural", que compreende os eixos: "desenvolvimento e educação social", "informação e comunicação", "produção cultural e design"; 4) a "formação para o trabalho em área comercial”, que compreende os eixos: "gestão e negócios" e "turismo, hospitalidade e lazer"; 5) a "formação para o trabalho em áreas diversas", que compreende os eixos: "militar", "segurança" e "infraestrutura". Além dessas subcategorias, incluímos a subcategoria "formação para o trabalho docente nos CSTs". Embora a formação docente não esteja presente nos eixos formativos do CNCSTs, por se tratar de outra modalidade de graduação, a inclusão do notório saber como requisito para a docência na educação técnica e profissional pela Lei $\mathrm{n}^{\circ}$ 13.415/2017 (BRASIL, 2017a) torna oportuna a inclusão dessa subcategoria.

A segunda categoria engloba as produções científicas que tomaram como objeto elementos referentes à "Política e Regulação dos CSTs". Os temas política e regulação relacionam, principalmente, conhecimentos das áreas: história, economia e sociologia. Partindo dessa compreensão, dividimos esta categoria em 07 subcategorias: 1) produções científicas relacionadas à história dos CSTs; 2) produções científicas relacionadas aos reflexos econômicos decorrentes da implementação dos CSTs; 3) produções científicas relacionadas aos reflexos sociais decorrentes da implementação dos CSTs; 4) produções científicas relacionadas aos impactos na saúde de pessoas envolvidas nos CSTs; 5) produções científicas voltadas à análise da gestão dos CSTs; 6) produções científicas relacionadas ao fundamento teórico que impulsionou a criação de CSTs; e 7) produções científicas relacionadas às questões de gênero nos CSTs.

A terceira categoria diz respeito às produções científicas que tomaram como objeto “Aspectos Pedagógicos dos CSTs". Considerando as áreas que compõem a Pedagogia, dividimos esta categoria em 07 subcategorias: 1) produções científicas que analisaram algum aspecto referente ao currículo dos CSTs; 2) produções científicas que analisaram algum aspecto referente à didática dos CSTs; 3) produções científicas que analisaram algum aspecto referente à política pedagógica dos CSTs; 4) produções científicas que analisaram algum aspecto 
referente à avaliação dos CSTs; 5) produções científicas que analisaram algum aspecto referente ao estágio supervisionado nos CSTs; 6) produções científicas que analisaram algum aspecto referente à evasão nos CSTs; e, 7) produções científicas que analisaram algum aspecto referente à política de inclusão nos CSTs.

A quarta categoria é para inclusão de outras produções científicas que não se adequam às categorias organizadas, mas dizem respeito aos CSTs, e a quinta categoria engloba as produções científicas que não dizem respeito aos CSTs, mas foram encontradas a partir de busca pelas palavras-chave.

Essa organização das produções científicas em categorias e subcategorias demonstra que cerca de $40 \%$ dos itens levantados se referem a aspectos pedagógicos dos CSTs; $25 \%$ referemse a aspectos políticos e regulação dos CSTs; 7\% se referem a aspectos profissionais nos CSTs; $28 \%$ não tinham relação com nenhum aspecto relevante acerca dos CSTs, apenas os mencionavam este grau acadêmico no corpo do texto, no resumo ou nas palavras-chave; e menos de $0,3 \%$ se encaixam na categoria “outros". A partir desta primeira análise, foi possível refinar o quantitativo de produções científicas sobre os CSTs levantadas para 476, uma vez que eliminamos a produções que não traziam em seu conteúdo os CSTs como objeto de análise, apenas os mencionavam por alguma razão específica. Então nos debruçamos para uma análise mais aprofundada destas 476 produções científicas dos seguintes tipos: 01 palestra, 02 pôsteres, 18 artigos, 366 dissertações e 89 teses.

Tabela 02: Número de produções científicas levantadas, por categoria e subcategoria de análise - 2017

\begin{tabular}{lrr}
\hline CATEGORIAS/SUBCATEGORIAS & $\mathbf{N o}$ & $\mathbf{\%}$ \\
\hline Aspectos Pedagógicos & $\mathbf{2 6 4}$ & $\mathbf{3 9 , 6}$ \\
\hline CURRÍCULO & 87 & 13,1 \\
\hline AVALIAÇÃO & 64 & 9,6 \\
\hline DIDÁTICA & 55 & 8,3 \\
\hline POLÍTICA PEDAGÓGICA & 39 & 5,9 \\
\hline EVASÃO & 12 & 1,8 \\
\hline INCLUSÃO & 4 & 0,6 \\
\hline ESTÁGIO SUPERVISIONADO & 3 & 0,5 \\
\hline Política e Regulação & $\mathbf{1 6 0}$ & $\mathbf{2 4 , 0}$ \\
\hline HISTÓRIA & 54 & 8,1 \\
\hline REFLEXOS ECONÔMICOS & 48 & 7,2 \\
\hline REFLEXOS SOCIAIS & 21 & 3,2 \\
\hline FUNDAMENTO TEÓRICO & 16 & 2,4 \\
\hline GESTÃO & 13 & 2,0 \\
\hline REFLEXOS NA SAÚDE & 5 & 0,8 \\
\hline
\end{tabular}




\begin{tabular}{|rrr}
\hline QUESTÕES DE GÊNERO & 3 & 0,5 \\
\hline Aspectos Profissionais & $\mathbf{5 0}$ & $\mathbf{7 , 5}$ \\
\hline FORMAÇÃO DOCENTE & 35 & 5,3 \\
\hline FORMAÇÃO COMERCIAL & 5 & 0,8 \\
\hline FORMAÇÃO DIVERSA & 4 & 0,6 \\
\hline FORMAÇÃO AMBIENTAL & 3 & 0,5 \\
\hline FORMAÇÃO CULTURAL & 2 & 0,3 \\
\hline FORMAÇÃO INDUSTRIAL & 1 & 0,2 \\
\hline Não Pertinente & $\mathbf{1 9 0}$ & $\mathbf{2 8 , 5}$ \\
\hline Outros & $\mathbf{2}$ & $\mathbf{0 , 3}$ \\
\hline TOTAL & $\mathbf{6 6 6}$ & $\mathbf{1 0 0 , 0}$ \\
\hline
\end{tabular}

Fonte: dados coletados pelos autores, elaboração própria

\section{Identificação de Tendências na Produção Científica Levantada}

Os temas "gestão" e "fundamentação teórica" dos CSTs têm sido objeto de pesquisas desde o ano de 1978 e, de modo frequente e regular, encontramos produções científicas datadas de 2001 a 2017, tendo o ano de 2009 como o mais produtivo, se considerarmos toda a extensão da série histórica da produção. Contudo, de modo inverso ao observado, quando organizamos as produções científicas encontradas por regiões geográficas, aquelas desenvolvidas no nível de mestrado e doutorado sobre os temas "gestão" e "fundamentação teórica" foram produzidos em maior número na Região Sul do país (40\%), seguida da região Sudeste (24\%), Nordeste (16\%), Centro-oeste (12\%) e Norte (8\%). Outra diferença encontrada especificamente sobre os temas "gestão" e "fundamentação teórica" em relação aos demais é que as instituições responsáveis por tais produções científicas são predominantemente públicas (mais de $90 \%$ ), enquanto menos de $10 \%$ são instituições de ensino superior privadas.

As produções científicas sobre "gestão" e "fundamentação teórica" dos CSTs estão concentradas em quatro principais temas: 1) relação entre capitalismo e CSTs; 2) relação entre a formação de nível superior e os CSTs; 3) modelos de gestão e os CSTs; e 4) demanda de criação de CSTs.

O tema com maior número de produções científicas (cerca de $40 \%$ do total) trata da relação entre o desenvolvimento do capitalismo e a criação/natureza dos CSTs. Essas produções científicas partem do contexto sócio-histórico da crise do capital, na passagem da década de 1960 para 1970, e do aprofundamento do neoliberalismo, para explicar a motivação central da criação, manutenção, e expansão dos CSTs (Cf.: CARVALHO, 2008; FEITOSA, 2014; FERNANDES, 2006; JUNQUEIRA, 2014; MORAIS, 2011; OLIVEIRA, 2001; PEREIRA, 2008; ROCHA, 2009; SANTOS, 2009). Portanto, é possível afirmar que o objetivo geral das 
produções científicas é, em síntese, analisar a relação Capital/Trabalho/Educação evidenciada no processo de implantação e desenvolvimento dos CSTs.

$\mathrm{O}$ primeiro ponto que as produções científicas componentes desse conjunto têm em comum é a tese de que o capitalismo realiza ajustes para enfrentar suas crises e tais ajustes afetam as políticas sociais. Nessa perspectiva, consideram que o próprio desenvolvimento do neoliberalismo surge como estratégia burguesa para a retomada das bases de acumulação de corroídas pela crise orgânica do capital vivenciada desde os anos 1970. A partir desse pressuposto, apontam a reforma do Estado e a reestruturação produtiva fomentadas no bojo do neoliberalismo como determinantes das proposições e implementação de diversas reformas educacionais, dentre as quais a criação e desenvolvimento dos CSTs.

Santos (2009) toma como fundamento a ideia de que a crise atual do capitalismo é estrutural. Embora a evidência da crise do capital seja uma ideia unânime entre os autores desse conjunto de produções científicas, há diferenças na concepção do tipo de crise que se desenvolve a partir da década de 1970. Há aquelas produções que tratam a crise como uma questão estrutural, focada nas quedas das taxas de lucratividade, e algumas que tratam a crise como sinal de esgotamento da sociabilidade burguesa, de modo que extrapola a esfera estrutural, concebendo a crise do capital como crise orgânica que engloba tanto a estrutura quando a superestrutura do capital. Nesse sentido, embora a descrição categórica do tipo de crise também não seja clara em alguns autores, é possível perceber alguns elementos que apontam para ideia de crise orgânica (Cf.: MORAIS, 2011, p. 109).

A organização da política educacional nesse contexto é marcada pelos valores sociais e econômicos oriundos do cerne do sistema do capital que se apresenta bem mais sofisticado no modelo neoliberal. Segundo Carvalho (2008) e Fernandes (2006), a regulação dos CSTs está fundamentada nesses valores (Cf. CARVALHO, 2008, p. 132-133).

Carvalho (2008) e Fernandes (2006) ainda pontuam um elemento-chave na essência dos CSTs: o tipo de conhecimento que esse modelo de ensino superior está pautado. Segundo eles, esse modelo é marcado pela fragmentação do conhecimento e sua concepção utilitarista (Cf.: FERNANDES, 2006, p. 138).

O segundo ponto que tais produções científicas têm em comum é a evidência da relação capital/trabalho/educação. É claro, portanto, o interesse em explicitar influências, impactos, interferências e preponderância da estrutura econômica na produção e reprodução da vida material, em que trabalho e educação são moldados pelo sistema do capital, a fim de atender suas demandas sistêmicas. Morais (2011) e Santos (2009) demarcam a condução do processo 
educativo, no âmbito da educação formal, pela lógica do sistema capitalista (Cf.: MORAIS, 2011, p. 111).

Santos (2009) ainda demarca que essa relação entre educação e trabalho no capitalismo, quando aponta a regulação do CSTs como ensino superior não universitário. Para ele, a predominância deste tipo de curso em instituições de ensino superior não universitárias evidencia a lógica dualista no interior da formação de nível superior. Nesse sentido, Santos (2009) se alinha também às produções científicas que tratam do segundo tema identificado na literatura, o qual descrevemos mais adiante, ao apontar a tensão entre dois modelos de ensino superior na política educacional brasileira (Cf.: SANTOS, 2009, p. 243).

O terceiro ponto de convergência é a tese de que os CSTs servem à formação de capital humano para atender às demandas do mercado. Direcionados pela lógica da empregabilidade, esses cursos superiores servem à educação da fração da classe trabalhadora ávida pela certificação como mecanismo de inclusão/manutenção do emprego no mercado de trabalho formal. Não obstante, a formação de um "novo trabalhador", conforme Feitosa (2014), ou de um "novo tipo de trabalhador", conforme Santos (2009), é uma exigência imposta pelo mercado às instituições educativas, inclusive aos CSTs (Cf.: FEITOSA, 2014, p. 103-104).

Santos (2009) pontua que esse "novo tipo de trabalhador" deve ser capaz de se colocar no mercado de trabalho, ainda que seja como gestor do próprio negócio. Nesses termos, evidencia a contradição que emerge da incapacidade dos CSTs em cumprir o papel de formar para autonomia, por se configurarem de modo estritamente profissional (Cf.: SANTOS, 2009, p. 246).

A contradição apresentada por Santos (2009) expõe a fragilidade do argumento presente no discurso dominante de que o papel dos CSTs é serem destinados, exclusivamente, à formação de mão de obra para o mercado de trabalho. Nesse aspecto, a essência do papel cumprido pelos CSTs aponta para interesses mais complexos na sociabilidade do atual contexto. Embora, conforme Morais (2011), o discurso da capacidade de empregabilidade a partir da certificação nos CSTs tenha aumentado seu nível de alcance. Fato que é possível ser atestado a partir do aumento expressivo no número de ingressos e de cursos (Cf.: MORAIS, 2011, p. 108). Além disso, Pereira (2008, p. 185) oferece mais elementos que evidenciam certo consenso em torno do discurso da empregabilidade a partir desse tipo de certificação:

O quarto ponto de convergência encontrado nas produções científicas foi a explicitação de que os CSTs figuram como mais uma forma de mercantilização da educação. A existência de um amplo mercado educacional ávido pelo lucro fortalece a expansão dos CSTs que se 
tornam mais uma dentre as mercadorias comercializadas pelo setor privado, conforme apontam Morais (2011), Santos (2009) e Feitosa (2014).

Nessa direção, Feitosa (2014) destaca o elemento "fetiche da mercadoria" que, conforme Marx (2017, p. 94), diz respeito às relações sociais entre coisas que atuam no campo da crença impondo valor para troca. Esse fetichismo, segundo Marx (2017), decorre do caráter social do trabalho na produção de mercadorias. Pautados nessa teoria, esse fetiche da certificação está eivado pela crença de alcance/manutenção do emprego e potencializa a corrida pelo diploma a qualquer custo, a despeito do desenvolvimento cognitivo (Cf.: FEITOSA, 2014, p. 104).

Ademais, o caráter mercantil que fundamenta os CSTs, segundo Santos (2009), intensifica a concepção empresarial na educação formal. A partir dessa lógica na qual o próprio Estado está se configurando, a política educacional brasileira organiza maneiras de gestão e financiamento que impactam na expansão de cursos, níveis e modalidades de ensino. Nesse sentido, a mercantilização educacional se expande internamente, nas estruturas dos sistemas de ensino, bem como externamente, alavancando o processo educativo no mercado educacional privado, como mercadoria (Cf.: SANTOS, 2009, p. 242-243).

O quinto ponto de confluência que encontramos nas produções científicas mencionadas diz respeito à função social dos CSTs para manutenção do capitalismo no sentido da alienação do trabalhador. A partir da pedagogia das competências, tais cursos estão estruturados dentro da lógica dualista da educação: uma educação para formar para o trabalho simples para ampla maioria da classe trabalhadora e uma educação de natureza científica e tecnológica para a formação para o trabalho complexo para a elite da classe trabalhadora (Cf.: ROCHA, 2009, p. 238).

Essa dualidade, até então explícita na dificuldade da classe trabalhadora para obter a certificação em nível superior, com a regulação dos CSTs, se evidencia na distinção de um curso de nível superior específico para atender às demandas da classe trabalhadora pelo nível educacional. Aliás, Rocha (2009), Santos (2009) e Junqueira (2014) expõem essa dualidade nos CSTs como expressão da divisão social do trabalho. Ao passo que os graus acadêmicos de bacharelado são destinados à formação para o trabalho complexo, os CSTs são destinados àqueles que executam o trabalho de menor complexidade (Cf.: JUNQUEIRA, 2014, p. 195).

Há a compreensão de que o aprofundamento da desigualdade é um dos elementos resultantes desse processo, haja vista o processo de transferência da responsabilidade de formação para o trabalhador, diante das exigências contidas no discurso hegemônico (Cf.: FRIEDMAN, 1984; BANCO MUNDIAL, 1996; HAYEK, 2010; DELORS, 1996; UNESCO, 
1968, 1990). Por outro lado, entende-se que a formação de dirigentes é continuamente financiada pelo Estado, reforçando a teoria de Estado mínimo para a classe trabalhadora e Estado benevolente para as demandas do capital. Também nesse aspecto, percebe-se o entendimento de que os CSTs fortalecem o consenso em torno da lógica de acumulação do capital, conforme Santos (2009, p. 249-250).

A manutenção dessa lógica afasta as possibilidades de emancipação da classe trabalhadora, conforme destaca Pereira (2008), embora a possibilidade de certificação nos CSTs tenha elevado o nível de formação da classe trabalhadora. A contradição explicitada nesse processo revela a disjunção entre o objetivo da política educacional e a efetividade dos resultados alcançados na perspectiva da classe trabalhadora (Cf.: PEREIRA, 2008, p. 187).

O sexto ponto de confluência entre as produções científicas trata da função social dos CSTs no sentido da conformação da classe trabalhadora mediada pela política pública de educação. Junto com o processo de alienação da classe trabalhadora, a necessidade de sua adaptação às condições de trabalho no estágio atual do capitalismo é suprida pelo acesso à certificação de nível superior em CSTs (Cf.: FEITOSA, 2014, p. 103).

O processo de ampliação das oportunidades educacionais ocorrido em escala global, inclusive nos países dependentes, contou com a participação ativa dos organismos internacionais. Este processo visa atender à demanda do capital diante da crise estrutural vivida desde os anos 1970 (Cf.: SOUZA; VEIGA, 2019; SOUZA, 2020). O discurso formulado no cerne das políticas educacionais massificou a hegemonia em torno da ideia de que a educação é uma necessidade e um direito, a despeito dos reais interesses que fundamentam tal discurso. Por outro lado, o acesso ao conhecimento, na perspectiva da emancipação da classe trabalhadora, não figura como objetivo desse processo educativo e a regulação do CSTs é uma evidência do tipo de formação destinada à classe trabalhadora. Mesmo neste contexto de desenvolvimento e sofisticação do sistema socioeconômico, o capital demanda o "gorila amestrado" idealizado por Taylor (1995). Diante disso, os CSTs servem à manutenção/alcance do consenso social em torno da demanda da classe trabalhadora por certificação de nível superior, conforme destaca Santos (2009, p. 242).

O sétimo ponto convergente entre as produções científicas diz respeito à evidência dos limites inerentes à certificação da classe trabalhadora a partir de uma perspectiva de educação pragmática e imediatista voltada exclusivamente à formação técnico-profissional. Tais limites potencializam a manutenção e reprodução do status quo do sistema capitalista, instrumentalizando a educação formal para esse fim (Cf.: JUNQUEIRA, 2014, p. 195). 
A tomada da política educacional formal como locus para o desenvolvimento da hegemonia em torno da sociedade de novo tipo está explícito no discurso propagado pelos organismos internacionais. Especificamente as políticas públicas para a Educação Profissional que tiveram impacto evidente. Carvalho $(2008$, p. 132) aponta que a real intencionalidade dessas políticas é a subsunção real do trabalho ao capital.

Essa perspectiva de formação humana é mais condizente com a ideia de conformação, tendo em vista que não democratiza o conhecimento, conforme esclarece Pereira (2008, p. 189). Desse modo, esse processo conformativo do humano de novo tipo acaba por alienar o trabalhador e subjugá-lo à reprodução do status quo, consciente ou inconscientemente.

O oitavo e último ponto que consideramos importante mencionar é o fundamento teórico materialista histórico e dialético utilizado nas produções científicas que compreendem o primeiro tema das produções científicas levantadas. Tal perspectiva analítica evidencia o desenvolvimento das políticas educacionais junto aos movimentos estruturais do sistema econômico, inter-relacionando os fenômenos pela perspectiva da totalidade, historicidade, complexidade, dialeticidade, praxidade, cientificidade e concreticidade. Embora poucas produções científicas tenham utilizado dados empíricos e a análise da maioria tenha se concentrado em fontes bibliográficas, os pontos confluentes apresentados demonstram o alinhamento tanto do quadro teórico metodológico, quanto dos resultados encontrados. Tal fato confere ainda mais força aos argumentos apontados pelos pesquisadores.

O segundo tema mais abordado nas produções científicas encontradas, cerca de $25 \%$ do total levantado, trata da relação entre a formação de nível superior e os CSTs (Cf.: ALKMIM, 2011; CIAVATTA, 2006; GOMES, 2009; GUIMARÃES, 2002; NOGUEIRA, 2015; SENFF, 2017; SILVA, 2016).

Diferentemente das produções científicas que compõem a subcategoria anterior, esse grupo de produções científicas têm poucos aspectos em comum quanto à fundamentação teórico-metodológica, embora estejam vinculadas pelo objetivo central que, sinteticamente, compreendemos ser a análise da função da formação em nível superior. Nesse sentido, delineamos três principais aspectos para os quais convergem as análises, conforme esclarecemos a seguir.

O primeiro ponto de convergência entre as produções científicas diz respeito à função da formação em nível superior, mais especificamente ao fato de os cursos tecnólogos serem considerados como nível superior, embora sejam limitados à formação técnico-profissional. A tensão encontrada entre a função social da universidade e os limites/possibilidades de que ela 
seja alcançada a partir dos CSTs é apontada nesta subcategoria. Nesse sentido, evidencia a concepção de universidade presente nesse grau educacional que evoca e afirma a dualidade existente no campo da educação em nosso país (Cf.: GOMES, 2009, p. 95-97).

Um elemento que reforça a dualidade mencionada por Gomes (2009) é o fato de cerca de $70 \%$ dos CSTs terem sido ofertados por instituições privadas não universitárias, de acordo com o Censo da Educação Superior de 2017 (INEP, 2018). Esse elemento põe em evidência a tensão acerca da função social da universidade à medida que recorre ao modelo "não universitário" de instituição para oferta de ensino superior, ainda que tais cursos sejam direcionados à parcela da classe trabalhadora que não costuma integrar o corpo discente das universidades. Ao mesmo tempo em que difunde novo modelo de IES que fragmenta a indissociabilidade entre ensino, pesquisa e extensão e, estrategicamente, reforça o discurso de privatização das universidades públicas (Cf.: SILVA, 2016, p. 92).

A dualidade na proposição de um nível superior de caráter pragmático e imediatista mascara sua essência pelo uso estratégico do termo "tecnologia", embora a maioria absoluta dos CSTs ofertados pelas IES no Brasil não tenham nenhuma relação com a difusão de conhecimentos tecnológicos. Fato que pode ser observado no Censo da Educação Superior de 2017 (INEP, 2018), embora uma leitura breve do CNCSTs (BRASIL, 2016a) seja suficiente para chegar a essa conclusão. Nesta perspectiva, Senff (2017, p. 73) conclui a incoerência e inconsistência desse modelo de curso superior.

Seguindo essa perspectiva de novos modelos, durante o processo de expansão da Rede Federal de Educação Profissional Científica e Tecnológica, foram ampliadas também a oferta de ensino superior nessas instituições, incluindo também a oferta de CSTs. Conforme ressalta Ciavatta (2006, p. 929), as contradições evidenciadas nesse processo reforçam as críticas a dualidade no interior da política.

Em Guimarães (2002), como também em Silva (2016), percebe-se a acusação de condução do processo pelo mercado (Cf.: GUIMARÃES, 2002, p. 133-134).

As críticas apontadas para os CSTs, segundo Alkmim (2011, p. 88), podem auxiliar na reformulação desses cursos. Contudo, as contradições evidenciadas são elementos constitutivos dos CSTs e, portanto, estão imbricadas em sua essência. A reformulação desses cursos para torná-los capazes de promover uma educação profissional politécnica é uma expectativa vaga e difícil de ser sustentada. Sobretudo porque, conforme menciona Nogueira (2015, p. 129), o desenvolvimento humano para emancipação é a função social da educação politécnica. 
O segundo ponto de convergência entre as produções científicas do segundo tema diz respeito às possibilidades de desenvolvimento do conhecimento nos CSTs. A dicotomia entre teoria e prática (técnica) potencializada pela racionalidade tecnológica fomenta uma perspectiva de conhecimento fragmentado que infunde a concepção de educação para subalternidade. Essa tensão evidenciada nos CSTs por Gomes (2009) e Senff (2017) explicita a essência desse tipo de curso, uma vez que estabelece uma clara distinção de sua finalidade para os demais cursos superiores (Cf.: GOMES, 2009, p. 95-96).

As possibilidades de desenvolvimento do conhecimento para além no nível da aplicação/reprodução, estão condicionadas ao desenvolvimento do próprio processo de reflexão que se torna realidade à medida que os sujeitos estabelecem relações entre teoria e prática. Portanto, o enfoque no aspecto prático da técnica impõe limites para o acesso ao conhecimento e, conforme afirma Senff (2017, p. 72), configura um processo educativo para deformação.

O terceiro ponto convergente entre as produções científicas da subcategoria aponta para os reflexos econômicos dos CSTs no sentido de que o desenvolvimento profissional possibilite a empregabilidade. O discurso hegemônico aponta para a ascensão social por meio da certificação. Isso foi atestado nas produções científicas encontradas que reafirmam a relação entre as imposições de certificação dos profissionais pelo mercado de trabalho, contudo, algumas produções científicas afirmam a impossibilidade estabelecer a relação entre certificação e trabalho formal (Cf.: ALKMIM, 2011, p. 87).

Neste segundo bloco de produções científicas, observamos duas concepções implícitas nas análises. Uma delas vincula as contradições encontradas na política de educação profissional científica e tecnológica à dimensão estrutural econômica do capitalismo; outra, no entanto, vincula tais contradições às questões pontuais internas no desenvolvimento da política pública. Nesse sentido, podemos afirmar que, embora tais produções científicas tenham desenvolvido análises críticas sobre os CSTs, nem todas partiram da perspectiva da totalidade do fenômeno.

O terceiro tema mais encontrado nas produções científicas, que também compreende cerca $25 \%$ da subcategoria, concentra propostas de modelos de gestão para os CSTs ou para algum aspecto referente a esse grau de formação (Cf.: BENTES, 2015; BILESSIMO, 2007; GONDIM, 2010; ROLOFF, 2007; SCHNEIDER, 2005; SILVA, 2009; SOUTO, 1978).

O primeiro ponto de convergência entre as produções científicas está na abordagem à eficiência da gestão. A crença de que a gestão de qualidade, por meio de gerenciamento de recursos, planejamento estratégico e implementação de ferramentas gerenciais impacta o 
resultado a ser obtido. Esses elementos estão presentes nos textos de Bilessimo (2007), Gondim (2010), Schneider (2005), Silva (2009) e Souto (1978). Tais produções científicas estão fundamentadas pela lógica gerencial, na qual a perspectiva empresarial é a mais efetiva, e por isso a consideram como aquela que apresenta melhores resultados. Tal afirmativa que desqualifica o trabalho educativo das IES públicas se sustenta na perspectiva privatista do contexto da reforma do Estado. A partir desse movimento, a tentativa de mudar a administração pública para conferir-lhe caráter gerencial tem sido evidente, conforme aponta Schneider (2005, p. 171, 172).

A concepção do gerencialismo para gestão pública é mencionada por Gondim (2010, p. 125-126). Esse autor apresenta a ferramenta Balanced Scorecard (BSC) utilizada para avaliação da gestão estratégica no cerne do Plan Do Check Act ou Adjust (PDCA), que é um método de gestão estratégica em quatro passos: planejar, fazer, verificar e agir. Esses instrumentos desenvolvidos para gestão, no âmbito do gerencialismo, são destinados à avaliação dos resultados no processo produtivo. Portanto, visam medir a produtividade dos trabalhadores, a fim de controlar suas ações. Contudo, para além do controle da produção, esses instrumentos servem estrategicamente para o deslocamento da avaliação dos resultados do campo da estrutura para o campo da ação dos sujeitos sobre tal estrutura, como se as condições estruturais não impactassem de modo preponderante os resultados obtidos. A defesa de que uma gestão de qualidade é realizada por meio da criatividade para solucionar problemas ofusca a responsabilidade do Estado de prover os meios necessários para prestação de serviço público adequada e imputa à ação do "gerente" que deve criar soluções (Cf.: SOUTO, 1978, p. 24-25). Fica clara, portanto, a condução ideológica do setor privado sobre a administração pública. A Nova Gestão Pública, nesse sentido, nada mais é que inserção das leis do mercado na esfera pública, de tal maneira que os recursos públicos sejam racionalizados ao máximo possível a avaliação da falta de qualidade desses serviços seja responsabilidade do servidor (Cf.: SILVA, 2009, p. 189).

O segundo ponto de convergência entre as produções científicas desta subcategoria, que segue a mesma perspectiva do ponto anterior, diz respeito à análise otimista da realidade, como evidenciam Gondim (2010), Schneider (2005) e Roloff (2007). A gestão educacional de excelência é apontada como fórmula para o alcance do objetivo de certificação (Cf.: GONDIM, 2010, p. 128).

Com base nessa perspectiva otimista da realidade, a intensificação da precariedade evidente no âmbito das instituições públicas é mencionada como exemplo de gestão que 
funciona ou não. Assim, os prêmios "inovação" buscam dar visibilidade aos modelos "de sucesso" e fundamentar o discurso hegemônico acerca da excelência da gestão empresarial (Cf.: ROLOFF, 2007, p. 125).

Essa concepção empresarial de gestão, no âmbito da educação formal, toma como palco os CSTs, como podemos notar em Schneider (2005, p. 174).

O terceiro ponto de convergência é a proposição de sugestões para trabalhos futuros e recomendações para implementação de medidas. Esse elemento encontrado nas produções científicas desta subcategoria evidencia o fomento à pedagogia política do capital a partir da produção científica, cuja finalidade é a propagação e fortalecimento do discurso presente na política pública de Educação Profissional Científica e Tecnológica que implementa os CSTs.

O quarto ponto de convergência encontrado, e que está alinhado ao terceiro, é a metodologia adotada nas produções científicas. A realização de produções científicas com aplicação prática dos modelos criados nas instituições que serviram de campo para produção da pesquisa tem como finalidade a demonstração prática do projeto desenvolvido. Tal demonstração funciona pedagogicamente como instrumento de convencimento da sociedade ao formato desenvolvido. Nesse sentido, há produção científica nessa subcategoria que conclui a efetividade da gestão nas IES privadas, conforme notamos em Silva (2009, p. 90).

Há também produção científica que refuta o alto custo/aluno na gestão de IES pública, como observamos em Bentes (2015). Ambas as evidências demonstram o fundamento eivado pela lógica empresarial ocupando espaços na produção acadêmica para promoção do discurso hegemônico (Cf.: BENTES, 2015, p. 85).

Não é nossa intenção aqui refutar ou mesmo questionar os resultados das produções científicas, mas analisar aspectos que fundamentam o discurso privatista que parte da desqualificação dos setores públicos, ao mesmo tempo em que avoca a ideia de qualidade dos setores privados. Inequivocamente, podemos afirmar que a exaltação da gestão privada em detrimento da gestão pública é eivada de contradições e interesses, como também figura como estratégia de conformação no bojo da reforma do Estado cujo objetivo principal é a reorientação do uso do fundo público em favor do grande capital.

O quarto e último tema encontrado dentre as produções científicas levantadas, corresponde a cerca de $10 \%$ do total e está relacionado à proposição de criação/implantação de CSTs para o atendimento de demandas sociais ou econômicas (Cf.: AFONSO, 2013; CANDIDO, 2001; OLIVEIRA; ESCOTT, 2015). O tema em questão está presente nas três produções científicas, embora o objetivo de Afonso (2013) seja a criação do Curso Superior 
Tecnológico em Gestão de Projetos, o objetivo de Candido (2001) seja a verificação da viabilidade de implantação de CSTs, e Oliveira e Escott (2015) apontem para inserção de tais cursos no Sistema S. Assim, o que difere nessas produções científicas é o curso e o local, mas a proposta de aplicação do grau de ensino é semelhante em todos. Nesse sentido, tais produções científicas partem da concepção de que os CSTs são instrumentos importantes na política pública de educação (Cf.: AFONSO, 2013, p. 99-100). Além disto, constituem instrumento de democratização do ensino superior e, portanto, de justiça social. Com base nessa concepção, Candido (2001, p. 91) exalta os CSTs e propõe a modalidade de Educação à Distância para difusão desse nível educacional. Seguindo esta perspectiva, Oliveira e Escott (2015, p. 733) preconizam a ampliação dos cursos no Sistema $\mathrm{S}$ e o financiamento público da formação em nível superior em IES privadas pelo FIES e PROUNI.

\section{Conclusão}

A partir dos dados que foram expostos, concluímos que o número de produções científicas sobre os CSTs é extenso, contudo, diz respeito principalmente aos aspectos pedagógicos deste grau acadêmico.

Por conta de nosso interesse específico de mapear a produção científica sobre o objeto de análise de nossas pesquisas, procuramos analisar as produções científicas sobre a gestão e os fundamentos teóricos dos CSTs. Estas subcategorias totalizam tímido quantitativo, se comparadas ao número absoluto encontrado, contando com menos de 30 produções científicas (artigos, dissertações e teses) produzidas desde 1978 até 2017.

Metade das produções científicas encontradas evidenciam os vínculos, bem como as contradições presentes na proposição dos CSTs com o desenvolvimento atual do capitalismo. A outra metade está composta, em menor número, por produções científicas cujas análises evidenciam críticas a esse grau acadêmico, contudo vinculam tais críticas a questões factuais internas no bojo da política pública; e, em maior número, por produções científicas que fomentam o modelo de gestão adotado pelos CSTs como modelo a ser seguido e ampliado. Esse último grupo compreende quase metade dessas produções. Nesse sentido, podemos concluir que as produções científicas levantadas que tomaram como objeto de análise o fundamento teórico e a gestão dos CSTs compõem um universo fracionado em dois grandes grupos principais: um que fomenta o discurso hegemônico, e outro que parte de uma perspectiva crítica a esse grau acadêmico. 
Enfim, a produção científica sobre os CSTs tem figurado como campo de disputa entre concepções divergentes de capital/trabalho/educação. A concepção hegemônica propõe a política pública como estratégia de mediação do conflito de classe, fomentando a certificação a partir do conhecimento fragmentado para atender demandas imediatas do mercado de trabalho. A concepção contra-hegemônica vislumbra a possibilidade de emancipação humana por meio da educação omnilateral, ao mesmo tempo em que compreende que a educação imediatamente interessada serve como instrumento de conformação e alienação da classe trabalhadora, na medida em que a certificação está desvinculada da garantia de acesso ao conhecimento científico e tecnológico. Entretanto, mesmo nesse campo crítico não percebemos a ocorrência de produções científicas que apontem o caráter contraditório do conjunto dos CSTs no Brasil. Talvez a contradição mais evidente deste cursos seja o fato de que, ao mesmo tempo em que formam técnicos especializados na perspectiva da produção enxuta e flexível para atender à demanda empresarial, em sua maioria tratam-se de cursos ofertados pela iniciativa privada, na modalidade de Educação a Distância, cujo propósito é formar para o desemprego e a precariedade (SOUZA, 2020). Para isto, as propostas pedagógicas da maioria dos CSTs se amparam na ideologia da empregabilidade, do empreendedorismo e da sustentabilidade. $\mathrm{O}$ efeito mais perverso desta contradição é que em nome da empregabilidade, estes cursos comprem função importante na pedagogia política renovada do capital para educar ampla parcela da classe trabalhadora a encarar com naturalidade o caráter competitivo e excludente do mercado de trabalho.

\section{REFERÊNCIAS}

AFONSO, Vitor Abilio Sobral Dias. Educação em gestão de projetos: uma proposta para o ensino superior brasileiro. 2013. 115 f. Dissertação (Mestrado em Ciências da Computação). Universidade Federal de Pernambuco, Recife, 2013.

ALKMIM, Giuliano Viana de. Curso superior de tecnologia e bacharelado: um estudo sobre a mudança ocorrida na formação profissional em administração no Instituto Federal de Educação, Ciência e Tecnologia do Norte de Minas Gerais - Campus Januária. 2011. 111 f. Dissertação (Mestrado em Educação). Universidade de Brasília, Distrito Federal, 2011.

BANCO MUNDIAL. Prioridades y estrategias para la educación: examen del Banco Mundial. Washington (DC), World Bank, 1996. 194 p.

BENTES, Anderson Carlos Lima. Um modelo de apuração de custos/aluno aplicado ao instituto federal de educação, ciência e tecnologia do Amazonas - IFAM. 2015. 93 f. 
Dissertação (Mestrado em Engenharia de Produção). Universidade Federal do Amazonas, Manaus, 2015.

BILESSIMO, Simone Meister Sommer. Modelo para gestão do curso de tecnologia em cerâmica da UNESC. 2007. 178 f. Tese (Doutorado em Engenharia de produção). Universidade Federal de Santa Catarina, Florianópolis, 2007.

BRASIL. Lei $\mathbf{n}^{\mathbf{0}}$ 13.415, de 16 de fevereiro de 2017. Altera as Leis $\mathrm{n}^{\mathrm{os}}$ 9.394, de 20 de dezembro de 1996, que estabelece as diretrizes e bases da educação nacional, e 11.494, de 20 de junho 2007, que regulamenta o Fundo de Manutenção e Desenvolvimento da Educação Básica e de Valorização dos Profissionais da Educação, a Consolidação das Leis do Trabalho

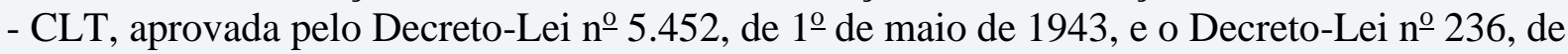
28 de fevereiro de 1967; revoga a Lei n-11.161, de 5 de agosto de 2005; e institui a Política de Fomento à Implementação de Escolas de Ensino Médio em Tempo Integral. Brasília, DF, 2017a. Disponível em: <http://www.planalto.gov.br/ccivil_03/_ato20152018/2017/lei/L13415.htm>. Acesso em: 24/04/2017.

BRASIL. Lei $\mathbf{n}^{0}$ 9.394, de 20 de dezembro de 1996. Estabelece as diretrizes e bases da educação nacional. Brasília, DF, 1996a. Disponível em:

<http://www.planalto.gov.br/ccivil_03/leis/L9394.htm>. Acesso em: 24/04/2017.

CANDIDO, Jorge. Viabilidade de implantação de cursos superiores de tecnologia. 2001. 179 f. Dissertação (Mestrado em Engenharia de Produção). Universidade Federal de Santa Catarina, Florianópolis, 2001.

CARVALHO, Brígida Maria Pimenta. A educação profissional tecnológica de graduação sob os impactos do neoliberalismo. 2008. 142 f. Dissertação (Mestrado em Educação). Universidade Federal de Uberlândia, Uberlândia, 2008.

Ciavatta (2006, p. 929),

CIAVATTA, Maria. Os Centros Federais de Educação Tecnológica e o ensino superior: duas lógicas em confronto. Educação e Sociedade, Campinas, v. 27, n. 96 - Especial, p. 911-934, out $/ 2006$.

DELORS, Jacques. Educação, um tesouro a descobrir: relatório para a UNESCO da Comissão Internacional sobre Educação para o século XXI. São Paulo: UNESCO/Cortez, 1996. $288 \mathrm{p}$.

FEITOSA, Cristiamari Carvalho. Trabalho e educação: uma reflexão sobre a formação de tecnólogos. 2014. 119 f. Dissertação (Mestrado em educação). Universidade Tuiuti do Paraná, Tuiuti, 2014.

FERNANDEZ, Ciro Francisco Burgos. Neoliberalismo e os cursos superiores de tecnologias no Brasil. 2006. 157 f. Dissertação (Mestrado em educação). Pontifícia Universidade Católica do Paraná, Curitiba, 2006.

FRIEDMAN, Milton. Capitalismo e liberdade. São Paulo: Abril Cultural, 1984. 236 p.

GOMES, Sandra Suely da Silva. Políticas educacionais para a educação tecnológica: a proposta do Curso Superior de Tecnologia em Gestão de Recursos Humanos da FAP e o 
histórico dualismo na educação brasileira. 2009. 118 f. Dissertação (Mestrado em educação). Universidade Federal do Pará, Belém, 2009.

GONDIM, Terezinha de Jesus Peres. A ação do coordenador do curso de graduação tecnológica em Instituição de Ensino Superior Privado em um Ambiente de Gestão Estratégica. 2010. 144 f. Dissertação (Mestrado profissionalizante em políticas públicas e gestão da educação superior). Universidade Federal do Ceará, Fortaleza, 2010.

GRAMSCI, Antonio. Cadernos do Cárcere - Introdução ao estudo da filosofia. A fiosofia de Benedetto Croce. Traduzido por Carlos Nelson Coutinho. Rio de Janeiro: Civilização Brasileira, 1999. Vol. I [494 p.].

GRAMSCI, Antonio. Cadernos do Cárcere - Notas sobre o Estado e a Política. Traduzido por Carlos Nelson Coutinho, Luiz Sérgio Henriques \& Marco Aurélio Nogueira. Rio de Janeiro: Civilização Brasileira, 2000a. Vol. III [428 p.].

GRAMSCI, Antonio. Cadernos do Cárcere - os Intelectuais. O princípio Educativo. Jornalismo. Traduzido por Carlos Nelson Coutinho. Rio de Janeiro: Civilização Brasileira, 2000b. Vol. II [334 p.].

GRAMSCI, Antonio. Cadernos do cárcere - Temas de cultura. Ação Católica.

Americanismo e fordismo. Traduzido por Carlos Nelson Coutinho \& Luiz Sérgio Henriques. Rio de Janeiro: Civilização Brasileira, 2001. Vol. IV [394 p.].

GUIMARÃES, Adriana Aparecida. A concepção e o modelo de universidade dos cursos superiores de tecnologia do Centro Federal de Educação Tecnológica do Paraná: o caso da unidade de Ponta Grossa. 2002. 181 f. Dissertação (Mestrado em tecnologia) - Centro Federal de Educação Tecnológica do Paraná, Curitiba, 2002.

HAYEK, F. A. O caminho da servidão. São Paulo: Instituto Ludwig von Mises Brasil, 2010. $232 \mathrm{p}$.

INEP. Inepdata: Censo da educação superior, microdados de 2017. Brasília, DF: 2018. Disponível em: <http://portal.inep.gov.br/web/guest/microdados>. Acesso em: 05/06/2019.

JUNQUEIRA, Victor Hugo. Educação, trabalho e ideologia: análise da relação agronegócio e educação na região de Ribeirão Preto - SP. 2014. 212 f. Dissertação (Mestrado em educação). Universidade Federal de São Carlos, São Carlos, 2014.

MANACORDA, Mario Alighiero. Marx e a pedagogia moderna. $3^{\text {a }}$ Ed. Campinas (SP): Átomo \& Alínea, 2017. 222 p.

MARX, Karl. O capital: crítica da economia política. Livro 1. Rio de Janeiro: Civilização Brasileira, 2017. 571 p.

MARX, Karl; ENGELS, Friedrich. Textos sobre educação e ensino. Campinas, SP: Navegando, 2011. 142 p.

MORAIS, Frederico Dourado Rodrigues de. A relação entre escola e trabalho na lógica do capital: os cursos superiores em tecnologia no Brasil em debate. 2011. 116 f. Dissertação (Mestrado em educação). Universidade Federal de Goiás, Goiânia, 2011. 
NOGUEIRA, Christiano. As concepções de homem, natureza e trabalho de alunos dos cursos de Técnico em Meio Ambiente e Tecnólogo em Gestão Ambiental do campus Visconde da Graça do Instituto Federal Sul-rio-grandense. 2015. 138 f. Tese (Doutorado em educação ambiental). Universidade Federal do Rio Grande do Sul, Porto Alegre, 2015.

OLIVEIRA, Adriana Rivoire Menelli de; ESCOTT, Clarice Monteiro. Políticas públicas e o ensino profissional no Brasil. Ensaio: avaliação de políticas públicas educacionais. V.23, n. 88, p. 717-738, jul-set/2015.

OLIVEIRA, Maria Auxiliadora Monteiro. A reforma do ensino profissional: desmantelamento da educação tecnológica ministrada pelo CEFET-X? Artigo. In: $24^{\text {a }}$ Reunião da ANPED, 2001, Caxambu (MG). Trabalhos. Caxambu (MG): ANPED, 2001. V. 1 , p. 1-16.

PEREIRA, Francisco. (Im)possibilidades da construção de uma educação emancipadora em cursos tecnológicos: uma abordagem a partir de dois cursos localizados em Goiânia e Anápolis. 2008. 196 f. Dissertação (Mestrado em educação). Pontifícia Universidade Católica de Goiás, Goiânia, 2008.

PISTRAK, Moisey M. Ensaios sobre a escola politécnica. São Paulo: Expressão Popular, 2013. 256 p.

PISTRAK, Moisey M. Fundamentos da Escola do Trabalho. São Paulo: Expressão Popular, 2000. 288 p.

ROCHA, Mariza Brandão. Metamorfose dos cursos superiores de tecnologia o brasil: Política de Acesso à Educação Superior em um Estado Burguês. 2009. 248 f. Tese (Doutorado em educação). Universidade Federal Fluminense, Niterói, 2009.

ROLOFF, Mário Lucio Proposta de um modelo de gestão tecnológica baseado em ferramentas software livre - estudo de caso do curso superior de Tecnologia em Automação Industrial do CEFET-SC. 2007. 141 f. Dissertação (Mestrado profissionalizante em administração). Universidade do Estado de Santa Catarina, Florianópolis, 2007.

SANTOS, José Deribaldo Gomes dos. Graduação tecnológica no Brasil: critica à expansão de vagas no ensino superior não universitário. 2009. 256 f. Tese (Doutorado em educação). Universidade Federal do Ceará, Fortaleza, 2009.

SCHNEIDER, Maria Clara Kaschny. Modelo de avaliação da gestão de instituição de cursos superiores de tecnologia.2005. $207 \mathrm{f}$. Tese (Doutorado em engenharia de produção). Universidade Federal de Santa Catarina, Florianópolis, 2005.

SENFF, Gerson. A formação no ensino superior tecnológico: estudo sobre a legislação normativa. 2017. 78 f. Tese (Doutorado em educação). Pontifícia Universidade Católica de São Paulo, São Paulo, 2017.

SILVA, Camila Sousa da. Perspectivas de formação do tecnólogo em gestão comercial. 2016. 100 f. Dissertação (Mestrado em educação nas ciências). Universidade Regional do Noroeste do Estado do Rio Grande do Sul, Ijuí, 2016. 
SILVA, Daniel Fernando Antonucci e. Modelo de maturidade de processos de gestão acadêmica em instituições privadas de ensino superior. 2009. 103 f. Dissertação (Mestrado profissionalizante em tecnologia). Faculdade de Tecnologia de São Paulo, São Paulo, 2009.

SOUTO, Múcio Antonio Sobreira. Um modelo setorial de previsão das necessidades de tecnólogos. 1978. 60 f. Dissertação (Mestrado em engenharia de produção). Universidade Federal de Santa Catarina, Florianópolis, 1978.

SOUZA, José dos Santos. Cursos superiores de tecnologia: a materialidade da formação enxuta e flexível para o precariado no Brasil. Trabalho Necessário, Vol. 18, no 36, p. 320342, mai.-ago./2020. DOI: https://doi.org/10.22409/tn.v18i36.38855

SOUZA, José dos Santos; VEIGA, Célia Cristina P. S. Determinantes sociais e políticos da regulamentação e fomento de cursos superiores de tecnologia no Brasil. Revista Práxis Educacional, Vitória da Conquista, Bahia, Brasil, v. 16, n. 38, p. 461-482, jan./mar. 2020.

TAYLOR, Frederick W. Princípios de administração científica. São Paulo: Atlas, 1995. $103 \mathrm{p}$.

UNESCO. Conferencia Internacional sobre Planeamiento de la Educación: informe final. Paris: UNESCO, 1968. 78 p.

UNESCO. Declaração mundial sobre educação para todos. Jomtien, 1990. 19 p.

\section{SOBRE OS AUTORES:}

\section{José dos Santos Souza}

Doutor em Sociologia pelo Instituto de Filosofia e Ciências Humanas da Universidade Estadual de Campinas (IFCH/UNICAMP), com estágio de pós-doutoramento em Educação pela Faculdade de Educação da UNICAMP. Atua como professor associado de economia política da educação e de política educacional do Departamento de Educação e Sociedade do Instituto Multidisciplinar da Universidade Federal Rural do Rio de Janeiro (UFRRJ), onde integra o quadro docente do Programa de Pós-Graduação em Educação, Contextos Contemporâneos e Demandas Populares (PPGEduc) e Coordena o Curso de Especialização em Gestão Educacional e lidera o Grupo de Pesquisas Sobre Trabalho, Política e Sociedade (GTPS). É editor da RTPS - Revista Trabalho, Política e Sociedade. E-mail: jsantos@ufrrj.br

iD http://orcid.org/0000-0001-5433-0812

\section{Célia Cristina Pereira da Silva Veiga}

Doutora em Educação pela Universidade Federal Rural do Rio de Janeiro (UFRRJ). Atua como Coordenadora de Ensino da Escola de Inteligência de Segurança Pública, da Subsecretaria de Inteligência, da Secretaria de Estado de Polícia Civil do Rio de Janeiro. É pesquisadora do Grupo de Pesquisas Sobre Trabalho Política e Sociedade (GTPS/UFRRJ). E-mail: celiacveiga@gmail.com

(iD http://orcid.org/0000-0003-4932-5968 